\title{
Scoping the budding and climate impacts on Eucalypt flowering: nonlinear time series decomposition modelling
}

\author{
$\underline{\text { I.L. Hudson }}{ }^{\text {a }}$ and M.R. Keatley ${ }^{\text {b }}$ \\ ${ }^{a}$ School of Mathematical and Physical Sciences, University of Newcastle, NSW, Australia \\ ${ }^{b}$ Dept of Forest and Ecosystem Science, University of Melbourne, Creswick, Victoria, Australia \\ Email: IreneLena.Hudson@gmail.com
}

\begin{abstract}
Often a phenophase such as flowering is considered in isolation. However, the timing of each phenophase is influenced by the previous (e.g. bud development rate influences the quantity and timing of flowering). This relationship has rarely been examined for eucalypts. In eucalypts, the development of buds often commences in a different season or, if in the same season, in different years, Climate influences on budding are therefore different to flowering. The effects of climate on the flowering of species has been previously determined (Hudson and Keatley, 2010b; Hudson et al., 2010, 2011b; Keatley and Hudson, 2000). This study includes modelling the influence of buds, in addition to climate, with respect to flowering. The Generalized Additive Model for Location, Scale and Shape (GAMLSS) is used to model the relationship between climate (mean monthly minimum, maximum temperatures and rainfall) during bud development and the flowering cycles of 2 eucalypt species (Eucalyptus leucoxylon and E. tricarpa) from the Maryborough region of Victoria between 1940 and 1962. Monthly behaviour (start, peak, finish, monthly intensity, duration and success) in budding and flowering was assessed using the indices of Keatley et al. (1999) and Keatley \& Hudson (2007).
\end{abstract}

Although E. tricarpa buds are significantly $(\mathrm{P}<0.01)$ positively and linearly related to higher minimum temperature $\left(\geq 9^{\circ} \mathrm{C}\right)$ both flowering and buds decrease significantly with maximum temperature $\left(>21^{\circ} \mathrm{C}\right)(\mathrm{P}<$ 0.01). Models of flowering including current bud status and climate show that E. tricarpa flowering is positively related to current budding intensities (buds $>4.5)(\mathrm{P}=0.0000)$ and increases with elevated rainfall (from 40 to approximately $88 \mathrm{~mm})(\mathrm{P}=0.045)\left(\mathrm{R}^{2}=60.8 \%\right)$. Inclusion of current budding as well as budding intensity 1 to 3 months prior to flowering in the models show E. tricarpa's flowering to significantly decrease and cease above $7.7^{\circ} \mathrm{C}$ minimum temperature, and increase with increased rainfall between appropriately 44 and $93 \mathrm{~mm}$. Budding 2 months prior is a positive influence $(\mathrm{P}<0.007)$, combined current budding and budding 2 months prior indicate flowering commences within the budding range of 4 to 6 $\left(\mathrm{R}^{2}=71.4 \%\right)$. For E. tricarpa minimum temperature is shown to drive increased budding but is associated with decreased flowering. Maximum temperature is associated with both increased budding and increased flowering for E. tricarpa; and flowering increases non-linearly both with elevated rainfall (from $40-90 \mathrm{~mm}$ ) and with increased buds. For E. leucoxylon buds are significantly $(\mathrm{P}<0.01)$ negatively and linearly related to elevated maximum temperature $\left(>23^{\circ} \mathrm{C}\right)(\mathrm{Z}=-3.2, \mathrm{P}<0.0001)$ and buds increase with increasing minimum temperature $\left(\left(\geq 9^{\circ} \mathrm{C}\right)(\mathrm{Z}=1.92, \mathrm{P}<0.08,10 \% \mathrm{sig})\right.$. Budding is significantly but nonlinearly influenced by rainfall: rain up to $40 \mathrm{~mm}$ has a positive influence and 40 to 80 negative. Models of E. leucoxylon flowering, which include current bud status and climate, show that E. leucoxylon's flowering is positively and nonlinearly related to current buds (buds $>5.5)(\mathrm{P}=0.000001)$ and decreases significantly with elevated minimum temperature $\left(\geq 8.5^{\circ} \mathrm{C}\right)(\mathrm{Z}=-2.38, \mathrm{P}<0.0001)\left(\mathrm{R}^{2}=42.6 \%\right)$. Inclusion of budding 1 to 3 months in the models show E. leucoxylon flowering to significantly increase with higher current bud quantity $(Z=2.57$, $\mathrm{P}<0.0001)$ and nonlinearly with respect to bud quantity 2 months prior $(\mathrm{P}<0.005)$ - with flowering commencing with bud intensity above 4.5 and decreasing when buds reach $7.0\left(\mathrm{R}^{2}=68.9 \%\right)$. This study has confirmed that for flowering to start, buds must have reached a particular maturity, before flowering occurs. For E. tricarpa this seems to occur when bud intensity has reached greater than 4.5, with a slightly lower value for E. leucoxylon, indicating that this species buds need longer to mature - this in turn further assists in separating the temporal flowering peaks between the two species. Additionally, a maximum flowering intensity is indicated with the inclusion of lagged budding: 6.0 for E. tricarpa and 7.0 for E. leucoxlyon. The inclusion of lagged budding found that budding two months prior was influential on flowering. Noteworthy is that 2 months is the most common period when temperature has the greatest influence on flowering (Hudson and Keatley, 2010a; Hudson et al., 2011a; Hudson et al., 2011c; Menzel and Sparks, 2006). These results indicate that it might not just be temperature, but temperature influencing the development of buds, which in turns influences flowering. This needs further work and the examination of additional species, but given that flowering is dependent on budding, this postulate makes sense (Primack, 1987).

Keywords: phenology, Australia, climate and budding thresholds, life-history, GAMLSS 


\section{INTRODUCTION}

Often a phenophase such as flowering is considered in isolation. However, the timing of each phenophase is influenced by the previous (e.g. bud development rate influences the timing and quantity of flowering) (Keatley and Hudson, 1998; Post et al., 2008; Primack, 1987). This relationship has rarely been examined for eucalypts (Keatley and Hudson, 1998; Keatley and Hudson, 2012). In eucalypts, the development of buds often commences in a different season or, if in the same season, it can occur in different years (Dooley et al., 2010; Law et al., 2000; Murray and Lutze, 2004). Climate influences on budding are therefore different to flowering. The influence of climate on eucalypt budding has also rarely been examined (Porter, 1978; Semple and Koen, 2010). Therefore to further our understanding of the influence of climate on flowering it is necessary to consider the influence of previous phenological stages and the interaction between them. This paper aims to examine the influence of climate on budding, effects of budding on flowering, as well as the interaction of climate and budding on flowering, via Generalized Additive Model for Location, Scale and Shape (GAMLSS) models. GAMLSS can deal with non-normal data and allow for a nonlinear relationship between the response (e.g. phenophase trend) and say, climatic predictors (e.g. Hudson, 2010; Hudson et al., 2010, 2011b), current or lagged or past phenophase (budding). This is achieved by replacing the conventional linear predictor function of values by an unspecified (nonparametric) smoother function. Recent phenological applications of GAMLSS involve the modelling of phenological data (e.g. flowering) in relation to climate (e.g. Hudson et al., 2010, 2011b; MacGillivray et al., 2010); and of leaf phenology and stages of two perennial herbaceous ferns, Dryopteris affinis ssp. affinis and Polystichum aculeatum (stages - from immature sori to spore release) in natural populations in Italy for 2 years (Landi et al., 2012); and the development of models for at-site probabilistic seasonal rainfall forecast (Villarini and Serinaldi, 2012).

\section{METHODS}

\subsection{Phenological and climate data}

We used the former Victorian Forest Commission records of budding and flowering of eucalypt species (Eucalyptus leucoxylon and E. tricarpa) and the field diaries of the Forest Overseer from Maryborough, Victoria between 1940 and 1962. Observations on the timing, quantity and distribution of flowering and budding of these species were collected on a monthly basis and placed into categories which had been predetermined by the Commission. Flowering and budding intensity of both species was quantified by assigning a rank value producing a categorical time series (Table 1). Flowering and budding behaviour (start, peak, finish, monthly intensity, duration and success) was defined using the methods of Keatley et al., (1999) and of Keatley and Hudson, (2007). Monthly minimum, maximum and rainfall data for the period 1936 to 1962 were provided by the Bureau of Meteorology.

Table 1. Descriptive terms to describe budding and flowering intensity and their assigned value.

\begin{tabular}{|l|l|l|l|l|}
\hline Observation parameter & Symbol & Description & \multicolumn{2}{|c|}{ Value } \\
& & & Flowers \\
\hline Quantity & $\mathrm{X}$ & No buds/No flowering & 0 & 0 \\
\hline & & Very scattered or isolated* & 0.5 & 0.5 \\
\hline & $\mathrm{L}$ & Light Crop/Flowering & 1 & 1 \\
\hline & $\mathrm{M}$ & Medium Crop/Flowering & 2 & 2 \\
\hline & $\mathrm{H}$ & Heavy Crop/Flowering & 3 & 3 \\
\hline Bud size & 1 & Small (recently formed) & 1 & N/A \\
\hline & 2 & Medium & 2 & N/A \\
\hline Distribution & 3 & Mature (ready to flower) & 3 & N/A \\
\hline & & Isolated* & 0.5 & 0.5 \\
\hline & $\mathrm{S}$ & Scattered & 1 & 1 \\
\hline & & Fairly General* & 1.5 & 1.5 \\
\hline & G & General & 2 & 2 \\
\hline
\end{tabular}

\subsection{Analyses}

The Generalized Additive Model for Location, Scale and Shape (GAMLSS), with a normal error distribution, cubic spline smoothing function and forwards stepwise selection procedure, was used to produce predictive models for flowering and of budding separately, and for relating flowering with budding as a covariate along with climate (budding predictors lagged up to 3 months prior). The response variables were flowering or 
budding and the normal error distribution (with log link function) was selected for fitting parameters. GAMLSS is a general framework for univariate regression type statistical problems which accommodates over dispersion, skewness and kurtosis in the response variable (which cannot be done via GLMs (Nelder and Wedderburn, 1972). GAMLSS was performed in the R statistical environment (R Development Core Team, 2012) using the GAMLSS package (Rigby \& Stasinopoulos (2005; 2007)).

\section{RESULTS}

\subsection{Mean budding and flowering behaviour}

There are general differences in the mean budding and flowering behaviour between E. tricarpa and E. leucoxylon. In E. tricarpa bud peak coincided with flowering commencement and leads the flowering peak by three months. In E. leucoxylon there is also a difference of three months, but with bud peak occurring in August, after flowering had commenced (Table 2). In this species flowering and budding peaks coincide.

Interestingly, buds are visible for the same amount time (4 months) before flowering commences. Both $E$. leucoxylon and E. tricarpa were observed carrying buds in all months of the year, but not every year, indicating the development of multiple crops and/or carryover of buds. On average buds commence development in January in E. leucoxylon and cease in December. In E. tricarpa bud development starts in December and finishes 11 months later in October. Eucalyptus leucoxylon carried both buds and flowers for all 23 years; that is a success rate of 1.00 . For E. tricarpa budding was slightly more successful $(0.92)$ than flowering (0.83). E. tricarpa budding failed in 1946/47and 1948/49, whereas flowering failed in 1947, 1949, 1958 and 1962.

Eucalyptus tricarpa commenced flowering late in 1943 (June) and 1956 (July); these were the lowest ranked years in total flowering intensity (excluding missed years and 1957). Four of the six early (commencing in January or February) flowering years $(1959,1950,1942,1946)$ in E. tricarpa were the highest rank in flowering intensity (ranging for 21 to 29.5). In the instances of 1951 and 1948 they were approximately middle ranking (eighth and ninth, respectively) in flowering intensity (10.5 and 12.5, respectively).

Late flowering (from June on) in E. leucoxylon occurred in 1941, 1943, 1954, 1958, 1960 and 1962. However, the years 1941, 1943 and 1958 were years in which flowering carried over into the following year, so although the intensity of these years was low, the total flowering intensity was not. The remaining years were the lowest ranked in flowering intensity. There were no years when flowering commenced early.

Table 2. Budding and flowering start, peak and finishing most probable months and missed years.

\begin{tabular}{|l|l|l|l|l|l|l|}
\hline Species & Phenophase & $\mathrm{N}$ & Start month & Peak month & Finishing month & Missed years \\
\hline E. tricarpa & Budding & 192 & December & April & Oct/Nov & $1946 / 47 ; 1948 / 1949$ \\
\hline & Flowering* & 276 & April & July & September & $1947 ; 1949 ; 1958 ; 1962$ \\
\hline E. leucoxylon & Budding & 133 & January & August & December & None \\
\hline & Flowering* & 276 & May & Aug/Sept & December & None \\
\hline *most likely months (Keatley and Hudson 2007) & \multicolumn{4}{l}{}
\end{tabular}

\subsection{Climate influences on budding}

Models of climate on E. tricarpa budding show that minimum temperature has a positive influence after a threshold of $\geq 9^{\circ} \mathrm{C}(\mathrm{P}<0.01)$ is reached. Maximum temperature has a negative influence with a threshold of $\geq 22^{\circ} \mathrm{C}(\mathrm{P}<0.01)$ being indicated when there is a significant decrease in budding. Rainfall was found not to be significant (Table 3 column 1). The influence of climate, however, is very weak $\left(\mathrm{R}^{2}=8.0 \%\right)$. In $E$. leucoxylon the influence of climate (minimum and maximum temperature and rainfall) is significant but not strong $\left(\mathrm{R}^{2}=27.8 \%\right)$. Minimum temperatures positively influence the development of buds with a threshold of $\geq 9.0^{\circ} \mathrm{C}(\mathrm{Z}=1.92, \mathrm{P}<0.08)$, maximum temperature negatively influences $\left(>23^{\circ} \mathrm{C}\right)(\mathrm{Z}=-3.2, \mathrm{P}<0.0001)$. The influence of rainfall on E. leucoxylon budding is nonlinear and benign until a threshold of $40 \mathrm{~mm}$ is reached after which rain is a negative influence $(\mathrm{P}=0.001)$.

\subsection{Climate and budding influences on flowering}

Models of flowering including current bud status and climate (maximum, minimum temperature and rainfall) show that E. tricarpa flowering is positively, but nonlinearly related to current budding intensities (buds $\geq$ 4.5) $(\mathrm{P}=0.0000)$ (Figure 2), and increases non-linearly with elevated rainfall ranging from approximately 40 to $88 \mathrm{~mm}(\mathrm{P}=0.045)\left(\mathrm{R}^{2}=60.8 \%\right)$, with rainfall above $88 \mathrm{~mm}$ having negative impact (Table 3 , column 3$)$. An 
examination of models for E. leucoxylon flowering showed that current bud status is also a positive and nonlinear influence (buds $>5.5)(\mathrm{P}=0.000001)$ (Figure 2), but that minimum temperature $\left(\geq 8.5^{\circ} \mathrm{C}\right)(\mathrm{P}<$ $0.0001)$ has a negative effect $\left(\mathrm{R}^{2}=42.6 \%\right)$. For E. tricarpa budding $(>4.5)$ was reached either on the month before flowering commenced $(28.6 \%)$ or two months prior $(71.4 \%)$ (Table 2$)$. In E. leucoxylon budding intensity $>5.5$ was reached either in the same month as flowering commenced $(61.5 \%)$ or one month prior to flowering (38.5\%). Budding 3 months prior is not a significant factor for flowering in either species.
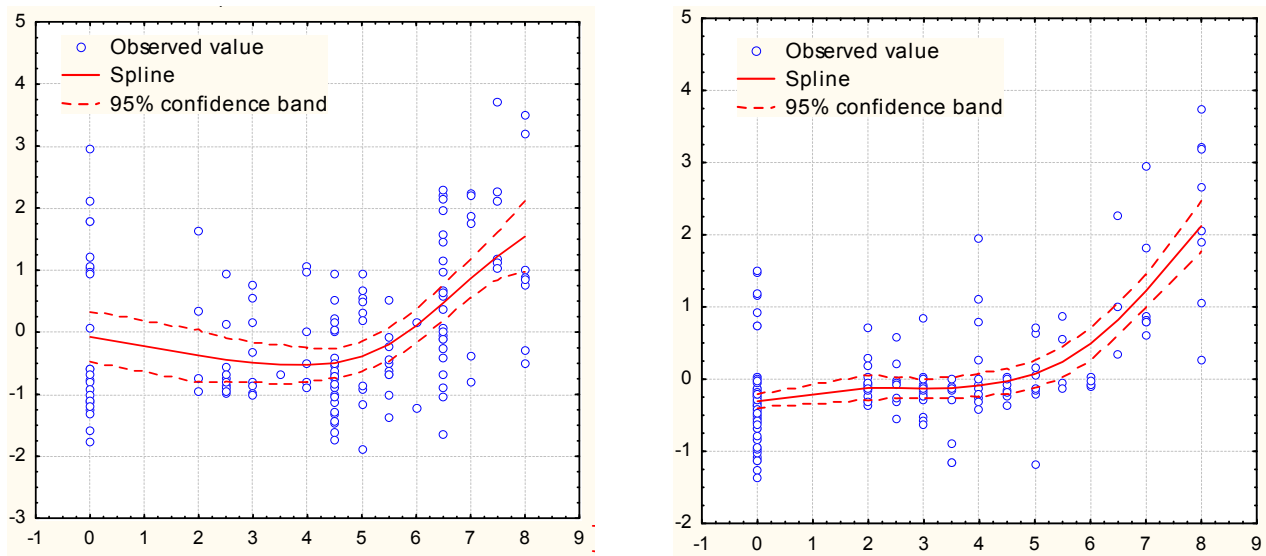

Figure 2. Partial residuals of cubic spline plots of current buds E. leucoxylon (left) and E. tricarpa (right). The dotted line shows the $95 \%$ confidence band around the cubic spline curve (solid line).

Table 3. Summary of the 4 models for E. tricarpa (y $\sim$ model notation) with significant predictors shown

\begin{tabular}{|c|c|c|c|c|}
\hline $\begin{array}{l}\text { [1] Budding } \\
\text { climate }\end{array}$ & $\begin{array}{l}\text { [2] Flowering } \\
\text { climate }\end{array}$ & $\begin{array}{l}\text { [3] Flowering } \sim \\
\text { climate }+ \text { current buds }\end{array}$ & \multicolumn{2}{|c|}{$\begin{array}{l}\text { [4] Flowering } \sim \text { climate }+ \text { current buds+ buds } 1-3 \\
\text { months back }\end{array}$} \\
\hline Minimum temp & & Rainfall & Minimum temp & Rainfall \\
\hline $\begin{array}{l}\text { Negative linear } \\
\text { influence with a } \\
\text { threshold of } \geq 22^{\circ} \mathrm{C} \\
(\mathrm{P}<0.01)\end{array}$ & $\begin{array}{l}\text { Negative linear } \\
\text { influence with a } \\
\text { threshold of } \geq 22^{\circ} \mathrm{C} \\
(\mathrm{P}<0.00001)\end{array}$ & $\begin{array}{l}\text { Nonlinearly related to } \\
\text { current budding } \\
\text { intensities (buds } \geq 4.5) \\
(\mathrm{P}=0.0000)\end{array}$ & $\begin{array}{l}\text { Nonlinearly related }- \\
\text { increased flowering with } \\
\text { current budding (buds } \geq \\
6.0)(\mathrm{P}<0.007)\end{array}$ & $\begin{array}{l}\text { Nonlinearly related } \\
\text { increased flowering with } \\
\text { bud } 2 \text { months prior }(\geq 4.0) \\
(P<0.007) \text {, }\end{array}$ \\
\hline $\mathrm{R}^{2}=8.0 \%$ & $\mathrm{R}^{2}=27.3 \%$ & $\mathrm{R}^{2}=60.8 \%$ & \multicolumn{2}{|l|}{$\left.\mathrm{R}^{2}=71.4 \%\right)$} \\
\hline
\end{tabular}
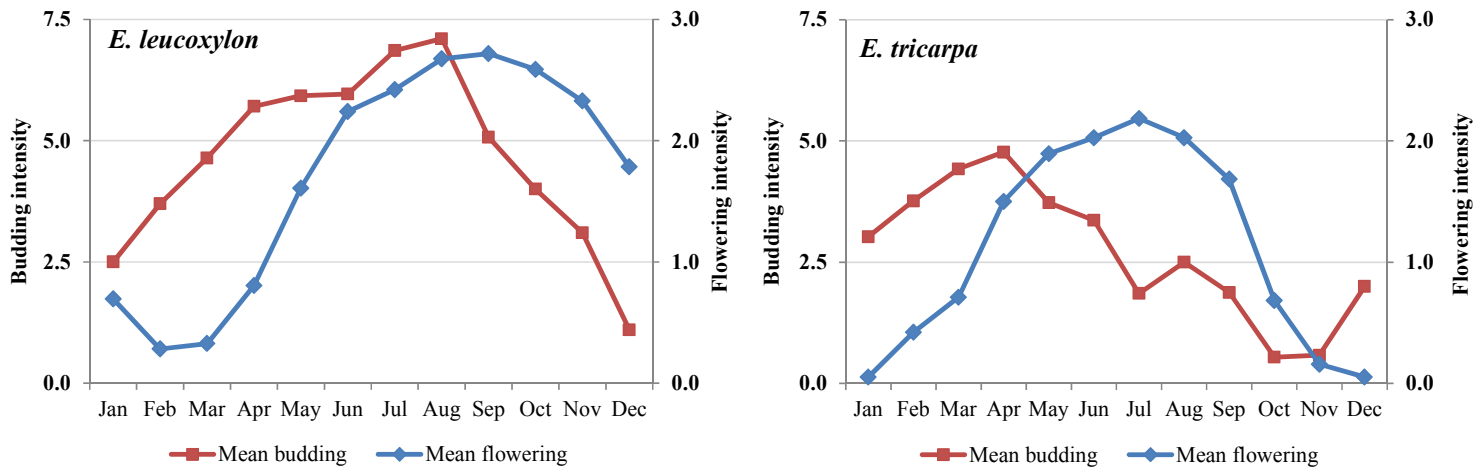

Figure 3. Mean budding and flowering of of buds E. leucoxylon (left) and E. tricarpa (right).

Inclusion of budding 1 to 3 months prior to flowering in the models show E. tricarpa flowering to significantly decrease and cease above $7.7^{\circ} \mathrm{C}$ minimum temperature and increase with elevated rain, ranging from approximately 44 and $93 \mathrm{~mm}$, and with increased current bud quantity 2 months prior $(\mathrm{P}<0.007)$ - with flowering commencing with buds above 4 or 6 , respectively $\left(\mathrm{R}^{2}=71.4 \%\right.$ ) (Table 3, column 3 and 4$)$. From Table 3 we observe that for E. tricarpa minimum temperature drives increased budding but elevated minimum temperature is associated with decreased flowering. Maximum temperature is associated with both increased budding and increased flowering for E. tricarpa and flowering increases non-linearly both with 
elevated rainfall (ranging from approximately 40 to $90 \mathrm{~mm}$ ) and with increased bud intensity. With the inclusion of budding 1 to 3 months in the models, flowering in E. leucoxylon significantly increases with higher current bud quantity $(\mathrm{Z}=2.57, \mathrm{P}<0.0001)$ and nonlinearly with respect to bud quantity 2 months prior $(\mathrm{P}<0.005)$, with flowering commencing when buds are above 4.5 and decreasing at 7.0 , respectively $\left(\mathrm{R}^{2}=68.9 \%\right)$. This can be explained in part by examining the mean budding and flowering intensities (Figure 3 , Table 2) which show that these budding values align closely with development of flowering (March to August). Flowering peaks one month later. Summary of the 4 models for E. leucoxylon is not reported here.

\section{DISCUSSION AND CONCLUSIONS}

\subsection{Mean budding and flowering behaviour}

These two species are taxonomically close, both are in the same series (Brooker, 2000; Pryor and Johnson, 1971), with morphologically similar flowers. Over a longer time period (1940 to 1970) the mean temporal production of flowers is significantly different: E. tricarpa flowering is positively skewed and E. leucoxylon negatively so (Hudson et al., 2010; Keatley, 1999). This rapid production of flowering in E. tricarpa is believed to quickly accustom potential pollinators to a new food source (Elzinga et al., 2007; Makino and Sakai, 2007; Thomson, 1980). As a consequence of their similar morphology, production of E. leucoxylon flowers may not need to be rapid so as to attract pollinators or enable them to adjust to a new food source. However, between 1940 and 1962 the mean production of flowers (and buds) is not significantly different from normal. E. tricarpa leads E. leucoxylon in the commencement of flowering and of peak flowering in the majority of years supporting the results of the earlier work (Hudson et al., 2010; Keatley, 1999). In relation to budding E. tricarpa's peak budding coincides with its flowering commencement, whereas E. leucoxylon budding aligns with peak flowering. Flowering in these species is overall synchronous (Keatley et al., 2004; Hudson et al., 2011f) which indicates facilitation occurring in these two species. This longer bud development period is one mechanism which contributes to temporal separation of flowering peaks, aids facilitation and therefore reduces competition for pollinators. These two species also significantly differ in the lifespan of individual flowers $(\mathrm{P}=0.001)$ : E. tricarpa 50.2 days and E. leucoxylon 30.3 days and nectar production: E. tricarpa 14.5 days and E. leucoxylon 26.0 days (Keatley 1999).

The carry-over of buds indicates late seasonal development, multiple crops and/or non favourable climate conditions for development (Ashton, 1975; Bassett, 2002). This occurred in E. leucoxylon between February 1941 and November 1942 and is confirmed by its extended flowering between June 1941 and November 1942. In addition extended flowering periods, from April 1946 to December 1947 and from April 1956 to December 1957, also indicate that carry over of buds occurred. Extended flowering (greater than 12 months) was not observed in E. tricarpa. However, carry-over of buds occurred between August 1940 and October 1941. Budding was also recorded in all months. Porter, 1978 also reports the carrying of buds throughout the year in E. sideroxylon (is now split into E. sideroxylon and E. tricarpa). The difference in success rates of budding and flowering is well known and E. tricarpa illustrates that flowering is dependent on budding but the production of buds does not guarantee flowering.

\subsection{Climate influences on budding}

The climatic influences on eucalypt budding has rarely been examined (Porter, 1978; Semple and Koen, 2010). Early work by Porter, 1978 indicates that mean temperatures above $17.5^{\circ} \mathrm{C}$ and monthly rainfall greater than $75 \mathrm{~mm}$ are the upper thresholds for positively influencing bud development in E. sideroxylon. This study delineated a lower threshold for bud development of $9^{\circ} \mathrm{C}$ minimum temperature and an upper threshold above $22^{\circ} \mathrm{C}$ maximum temperature for E. tricarpa. Rainfall was not found to be significant. The influence of temperature on E. leucoxylon's buds is similar to that of E. tricarpa: a lower threshold of $9^{\circ} \mathrm{C}$ minimum temperature and an upper threshold of above $23^{\circ} \mathrm{C}$ maximum temperature. These temperatures occur in Maryborough between November and March. Rainfall, however, was found to have a negative influence above $40 \mathrm{~mm}$. As these species commence budding within a month of each other, and this agreement between temperatures seems reasonable.

\subsection{Climate and budding influences on flowering}

The climate influences on the flowering of these species has been previously determined (Hudson and Keatley, 2010b; Hudson et al., 2010, 2011b; Keatley and Hudson, 2000). This study, which included the influence of buds with climate, has found that budding is a positive influence on flowering - an unsurprising result. However, it has confirmed buds must have reached a particular maturity before flowering occurs. For E. tricarpa this seems to occur when buds have reached greater than 4.5. This is a slightly lower value than for E. leucoxylon, indicating that this species buds may need longer to mature, which in turn further assists in 
separating the two species' flowering peaks. Additionally, a maximum flowering intensity is indicated with the inclusion of lagged budding: 6.0 for E. tricarpa and 7.0 for E. leucoxlyon; indicative of their respective mean peak values (4.8 and 7.1). The inclusion of lagged budding found that budding two months prior was influential on flowering - two months, being the most common period identified when temperature has greatest influence on flowering (Hudson and Keatley, 2010a; Hudson et al., 2011a; Hudson et al., 2011c; Menzel and Sparks, 2006). These results indicate that temperature influences bud development, which in turns effects flowering. This question about the complex interplay between climate and budding on flowering needs further work with the examination of additional species, but. given that flowering is dependent on budding, our postulate makes sense (Primack, 1987). Indeed for E. tricarpa minimum temperature drives increased budding, but elevated minimum temperature is associated with decreased flowering; whilst maximum temperature is associated with both increased budding and flowering. In this study a minimum temperature when flowering does not occur in E. tricarpa was delineated $\left(>7.7^{\circ} \mathrm{C}\right)$. This agrees with the mean minimum temperatures (greater than $9^{\circ} \mathrm{C}$ ) for the months when E. tricarpa is not in flower. However, as to why this lower temperature threshold became evident, only with the inclusion of buds in the model, requires further work.

\section{ACKNOWLEDGMENTS}

We thank The Dahl Trust for their support in the digitizing of the budding data.

\section{REFERENCES}

Ashton, D.H. (1975). Studies of flowering behaviour in Eucalyptus regnans F. Muell., Australian Journal of Botany, 23, 399-411.

Bassett, O.D. (2002). Flowering and seed crop development in Eucalyptus sieberi L. Johnson and E. globoidea Blakely in a lowland sclerophyll forest in East Gippsland, Victoria, Australian Forestry, 65(4), 237-254.

Brooker, M.I.H. (2000). A new Classification of the Genus Eucalyptus L'Her. (Myrtaceae), Australian Systematic Botany, 13, 79-148.

Dooley, G.M., M.D. Murray, M.T. Lutze, G.J. McCarthy, P.C. Perry, and P.C. Fagg (2010). Seedcrop development in Eucalyptus viminalis in High-Elevation Mixed Species forest of East Gippsland, Austalian Forestry, 73(1).

Elzinga, J.A., A. Atlan, A. Biere, L. Gigord, A.E. Weis, and G. Bernasconi (2007). Time after time: flowering phenology and biotic interactions, Trends in Ecology and Evolution, 22(8), 432-439.

Hudson, I.L. (2010). Interdisciplinary approaches: towards new statistical methods for phenological studies, Climatic Change, 100, 143-171.

Hudson, I.L., and M.R. Keatley (Eds.). (2010a). Phenological Research: Methods for environmental and climate change analysis. Dordrecht: Springer.

Hudson, I.L., and M.R. Keatley. (2010b). Singular spectrum analysis: climatic niche identification. In I.L. Hudson and M.R. Keatley (Eds.), Phenological Research: Methods for environmental and climate change analysis (pp. 393-424). Dordrecht: Springer.

Hudson, I.L., M.R. Keatley, and I. Kang. (2011a). Wavelets and clustering: methods to assess synchronization. In M. Valle, R. Munoz and J.M. Gutiérrez (Eds.), Wavelets: Classification, theory and applications (pp. 97-124): Nova Science Publishers.

Hudson, I.L., S.W. Kim, and M.R. Keatley. (2010). Climatic influences on the flowering phenology of four Eucalypts: a GAMLSS approach. In I.L. Hudson and M.R. Keatley (Eds.), Phenological Research: Methods for environmental and climate change analysis (pp. 209-228). Dordrecht: Springer.

Hudson, I.L., S.W. Kim, and M.R. Keatley. (2011b). Climate effects and temperature thresholds for Eucalypt flowering: a GAMLSS ZIP approach. Paper presented at the MODSIM2011, 19th International Congress on Modelling and Simulation. Modelling and Simulation Society of Australia and New Zealand, Perth Convention and Exhibition Centre in Perth, Western Australia, 12th - 16th December 2011.

Hudson, I.L., S.W. Kim, and M.R. Keatley. (2011c). Modelling lagged dependency of current and past climate on flowering: mixture transition state approach Climate and Society: 19th International Congress of Biometeorology. December 4th -8th The University of Auckland, New Zealand.

Hudson, I.L., M.R. Keatley, and S.Y. Lee (2011f). Using Self-Organising Maps (SOMs) to assess synchronies: an application to historical eucalypt flowering records. International Journal of Biometeorology, 55, 879-904.

Keatley, M.R. (1999). The Flowering Phenology of Box-Ironbark Eucalypts in the Maryborough Region, Victoria. Ph.D, The University of Melbourne.

Keatley, M.R., and I.L. Hudson (1998). The influence of fruit and bud volumes on Eucalypt flowering: An exploratory analysis, Australian Journal of Botany, 42(2), 281-304. 
Keatley, M.R., and I.L. Hudson. (2000). Influences on the flowering phenology of three eucalypts. In R.J. de Dear, J.D. Kalma, T.R. Oke and A. Aucliems (Eds.), Biometeorology and Urban Climatology at the Turn of the Century. Selected Papers from the Conference ICB-ICUC'99 (pp. 191-196). Geneva, Switzerland: World Meteorological Organisation.

Keatley, M.R., and I.L. Hudson (2007). A comparison of the long-term flowering patterns of Box-Ironbark species in Havelock and Rushworth forests, Environmental Modeling and Assessment, 12, 279-292.

Keatley, M.R., and I.L. Hudson. (2012). The influence of budding on the flowering of four eucalypt species. Paper presented at the Phenology 2012: Climate change impacts and adaptations, University of Michigan, Wisconsin, USA, Sept 10th - 13th.

Keatley, M.R., I.L. Hudson, and T.D. Fletcher. (1999). The use of long-term records for describing flowering behaviour: A case-study in Victorian Box-Ironbark Forests. In J. Dargavel and B. Wasser (Eds.), Australia's Ever-changing Forests IV (pp. 311-328). Canberra: Australian University Press.

Keatley, M.R., I.L. Hudson, and T.D. Fletcher (2004). Long-term flowering synchrony of Box-Ironbark eucalypts, Australian Journal of Botany, 52(1), 47-54.

Landi, M., A. Zoccola, G. Bacaro, and C. Angiolini (2012). Phenology of Dryopteris affinis ssp. affinis and Polystichum aculeatum: modeling relationships to the climatic variables in a Mediterranean area, Plant Species Biology. doi: 10.1111/1442-1984.12000

Law, B., L. Mackowski, and T. Tweedie (2000). Flowering phenology of myrtaceous trees and their relation to climate, environmental and disturbance variables in northern NSW, Austral Ecology, 25, 160-178.

MacGillivray, F., I.L. Hudson, and A.J. Lowe. (2010). Herbarium collections and photographic images: Alternative data sources for phenological research. In I.L. Hudson and Keatley M.R (Eds.), Phenological Research: Methods for environmental and climate change analysis (pp. 425-463). Dordrecht: Springer.

Makino, T.T., and S. Sakai (2007). Experience changes pollinator responses to floral display size: from sizebased to reward-based foraging, Functional Ecology, 21(5), 854-863.

Menzel, A., and T. Sparks. (2006). Temperature and plant development: phenology and seasonality. In J.I.L. Morison and M.D. Morecroft (Eds.), Plant Growth and Climate Change (pp. 70-95): Blackwell Publishing

Murray, M.D., and M.T. Lutze. (2004). Seedcrop development in Eucalyptus obliqua and Eucalyptus cypellocarpa in High elevation Mixed Species forests of East Gippsland (Vol. Research Report 387). Orbost: Forest Science Centre.

Nelder, J.A., and R.W.M. Wedderburn (1972). Generalized Linear Models, Journal of the Royal Statistical Society Series A, 135(3), 370-384.

Porter, J.W. (1978). Relationships between flowering and honey production of Red Ironbark, Eucalyptus sideroxylon (A. Cunn.) Benth., and climate in the Bendigo district of Victoria., Australian Journal of Agricultural Research, 29, 815-829.

Post, E., C. Pedersen, C.C. Wilmers, and M.C. Forchhammer (2008). Phenological sequences reveal aggregate life history response to climatic warming, Ecology, 89(2), 363-370.

Primack, R.B. (1987). Relationship among flowers, fruits and seeds, Annual Review of Ecology and Systematics, 18, 409-430.

Pryor, L.D., and L.A.S. Johnson. (1971). A Classification of the Eucalypts. Canberra: Australian National University.

Rigby, R.A., and D.M. Stasinopoulos (2005). Generalized Additive Models for Location, Scale and Shape, Applied Statistics, 54, 507-554.

Rigby, R.A., and D.M. Stasinopoulos (2007). Generalized Additive Models for Location Scale and Shape (GAMLSS) in R, Journal of Statistical Software 23, 1-46.

Semple, W.S., and T.B. Koen (2010). Reproductive Phenology of White Box (Eucalyptus albens Benth.) in the Southern Portion of its Range: 1997 to 2007, Proceeding of the Linnean Society of New South Wales, 131, 93-110.

Thomson, J.D. (1980). Skewed flowering distributions and pollinator attraction, Ecology, 61(3), 572-579.

Villarini, G., and F. Serinaldi (2012). Development of statistical models for at-site probabilistic seasonal rainfall forecast, International Journal of Climatology, 32, 2197-2212. doi: 10.1002/joc.3393 